\title{
A necessidade de exames no ensino básico e secundário
}

A Química, a par da Matemática e da Física, é uma ciência estruturante, e cujo conhecimento é fundamental para todos os cursos de ciências, desde as engenharias às medicinas, agronomias, etc. É também uma ciência cuja aprendizagem tem de ser sequencial, isto é, as bases fundamentais têm de ser apreendidas cedo, muito exercitadas intelectualmente, bem absorvidas e sedimentadas no espírito do aluno, e subsequentes conhecimentos têm de ir sendo aprendidos lenta mas solidamente, e só em condições de poderem entrar para a mente do aluno de modo que este as possa intelectualmente relacionar com as anteriores bases. De contrário, o conhecimento reduz-se a um amontoado de "frases" isoladas, eventualmente úteis para responder a "charadas científicas", mas sem qualquer utilidade para a vida prática ou mesmo para o conhecimento "puro" deste ramo da ciência. Infelizmente essas provas, a que alguns chamam "exames do $12 .^{\circ}$ ano" (não são realmente exames), não passam de "charadas", e é por demasiado evidente que quem escreve os enunciados [1] dessas provas não tem o adequado conhecimento científico para a tarefa de escrever enunciados de exames.

Ora, a actual situação no ensino básico e secundário é de molde a que a maioria dos alunos se arrasta até ao ensino superior sem absorver os necessários conhecimentos em todas as disciplinas, mas talvez seja na Química que o problema é mais grave. É verdade que há alunos que aí chegam com preparação suficiente (uns 10 a 20\%), e até alguns desses, digamos 1 a $2 \%$, com preparação melhor que os melhores de há 3 ou mais décadas. Os professores do ensino básico e secundário dedicam-se hoje aos alunos muito mais do que outrora, os programas e os livros (embora com muitas deficiências) talvez sejam melhores que os de outrora, e sobretudo há hoje um maior número de pais academicamente preparados para os auxiliarem, bem como há hoje, melhor que outrora, meios auxiliares de aprendizagem, tais como a "Internet", enciclopédias, a própria televisão se usada criteriosamente, etc.

Mas a tragédia para o futuro do nosso País é que os restantes 80 a $90 \%$ chegam ao ensino superior com lacunas muito profundas. O problema é que, no ensino superior, é tarde de mais para adquirirem as tais bases e, sobretudo, métodos de raciocínio e aprendizagem necessários para adquirirem uma formação sólida para depois desempenharem uma profissão a nível da verdadeira licenciatura. Depois, lá se vão arrastando, reprovando muitas vezes, mas também lá vão sendo aprovados, disciplina agora, disciplina logo, pois os júris de exames universitários não têm outro remédio senão procurarem facilitar a aprovação, de molde a não terem números demasiado elevados de reprovações, o que é politicamente (e até fisicamente) perigoso. E assim, lá vai o País tendo lufadas de licenciados que só o são no texto do diploma que Ihes derem.

É urgente travar esta degradante situação. Da mesma maneira que estamos a deixar às gerações futuras uma caótica situação no ordenamento do território (comparemos as nossas cidades com as da vizinha Espanha, ou com as da Alemanha ou do Reino Unido!), uma infuncional situação na justiça, etc., estamos também a criar uma situação no que respeita a futuros quadros técnicos profundamente calamitosa [2].

\section{Que fazer?}

Naturalmente haveria que actuar em muitos aspectos. Mas alguns (e.g. travar esta enorme mobilidade de professores de umas escolas para outras) têm custos políticos (e económicos) de tal modo elevados que não há, por enquanto, governo que consiga alterar significativamente a situação. Há contudo outro aspecto, perfeitamente exequível, e que daria um enorme contributo para meIhorar a eficiência do nosso ensino: repor exames no ensino básico e secundário. Mas que sejam verdadeiros exames e não "charadas" como agora acontece nas provas do $12 .^{\circ}$ ano. Assim, propomos exames nacionais no $12 .^{\circ}$ ano nos seguintes moldes, estendendo-se progressivamente aos $9 .^{\circ}, 6 .^{\circ}$ e $4 .^{\circ}$ anos, como o delineado no ponto 11 .

1. Duas provas ("chamadas") para cada disciplina, a $1 .^{\text {a }}$ a realizar na primeira semana de Junho e a 2. ${ }^{a}$ na primeira semana de Julho. Só a nota melhor destas duas provas, $\mathrm{Ni}$,

\footnotetext{
* Departamento de Química - Universidade de Coimbra, 3004-535 Coimbra (vlobo@ci.uc.pt)

${ }^{1}$ É pois claro que as notas dadas ao longo dos anos escolares não fazem qualquer tipo de média com a nota do exame. Servem sim para propor (ou não) o
} 
conta para classificação. Minimizam-se assim efeitos prejudiciais de causas fortuitas ${ }^{1}$ [4].

2. A nota de aprovação do $12 .^{\circ}$ ano, e consequentemente a da candidatura ao ensino superior é a média $\mathrm{M}$ dessas Ni notas (isto é, só essa média M conta para ordenação dos candidatos). O aluno tem de ter aprovação, isto é, 10 valores na tradicional escala de 0 a 20 valores, em cada uma das disciplinas da sua área, para se poder candidatar (tomando-se sempre a melhor das notas das duas chamadas). 0 aluno terá um certificado de frequência do $12 .^{\circ}$ ano com base na nota de admissão a exame.

Existindo exames nestes moldes, não se justificam provas de admissão ao ensino superior específicas de cada instituição deste. Tal criaria diferenças de critérios de instituição para instituição, o que seria muito prejudicial para o ensino em Portugal, para os candidatos que teriam de fazer muitas provas em sítios diferentes, e para o Orçamento do Estado que teria de suportar despesas injustificadas.

3. O júri nacional que elabora os enunciados dos exames deve ser constituído por personalidades que tenham um sólido conhecimento da respectiva matéria, podendo ser oriundos da indústria, do ensino secundário ou do superior, de institutos de línguas (e.g. British Council), escritores ou artistas de reconhecido mérito, etc. O Presidente do Júri deve garantir que os enunciados das provas de exame correspondam a situações realistas e cientificamente correctas. A situação que até agora se tem passado de serem dados enunciados com perguntas "erradas", isto é, conducentes a respostas contrárias à realidade, é totalmente inaceitável.

Naturalmente que os recursos humanos e materiais do Gabinete de Avaliação Educacional (GAVE) poderiam dar uma preciosa ajuda para a implementação destas propostas.
4. Os critérios de avaliação devem ser realistas e não baseados em preconceitos "educacionais" incompatíveis com a realidade da vida onde estamos inseridos.

O Presidente do Júri deve reunir com todos os elementos do júri e expor claramente as linhas gerais dos critérios de avaliação.

5. O júri deve reunir logo após cada exame (preferivelmente todos os membros no mesmo local geográfico, e.g. um departamento do Estado, um hotel) para rapidamente avaliar as provas e publicar os resultados. Estes devem sair pelo menos uma semana antes da segunda chamada, para que os exami-

\section{Os critérios de avaliação devem ser realistas e não baseados em preconceitos "educacionais" incompativeis com a realidade da vida onde estamos inseridos.}

nandos decidam a sua estratégia para a tal chamada de Julho. Por exemplo, os resultados do dia 1 de Junho deveriam sair até, digamos, 23 de Junho.

6. Caso logisticamente seja exequível, os alunos poderiam obter uma fotocópia da sua prova, logo que possível a seguir ao seu exame. Para reduzir papel, facilitar a avaliação, etc., a seguir a cada pergunta do enunciado haveria logo o espaço para a resposta. 0 enunciado do exame deve conduzir a um teste realizável por um aluno razoável em cerca de 3/4 do tempo total, e.g. 90 minutos se o exame for de 2 horas, dando tempo para o examinando pensar muito e escrever pouco; não deve ser uma maratona de longa escrita a contra-relógio. 0 examinando seria encorajado a pensar bem antes de escrever (a vida prática é assim), eventualmente a fazer um rascunho. As perguntas devem ser muito objectivas, tendo como resposta muito poucas palavras ou, quando aplicável, só a indicação (bem explícita) das operações matemáticas e o resultado final. Mais uma vez, é isso mesmo a vida prática.

7. Exactamente porque já há duas chamadas, e só a melhor nota é escolhida, acabaria o condenável sistema de pedido de revisão de provas. É que esse sistema cria a profundíssima injustiça de diferentes tratamentos só porque um teve dinheiro, "conhecimentos", etc., para pedir tal revisão, e outro não. É evidente que se alguém suspeitasse de um erro de forma (e.g. cotação mal somada) poderia escrever para o Presidente de Júri. Em caso de erros de forma graves por parte de um membro do júri, este deveria ter uma forte penalização.

8. Não pode haver nenhuma chamada só para um grupo específico de examinandos. É profundamente injusta a actual situação de chamadas específicas para uma classe de examinandos, às quais outros examinandos não têm acesso. Se se acha que 2 chamadas (Junho e Julho) é pouco, poder-se-ia fazer mais, mas sempre para todos os candidatos e sempre com o princípio de só contar a melhor nota. A ordenação dos candidatos ao ensino superior é algo muito sério, e as injustiças que actualmente se verificam são inaceitáveis. Veja-se o que acontece com o chamado Ensino Recorrente: parece que mais de $30 \%$ dos alunos que entraram para uma dada Faculdade de Medicina vieram do Ensino Recorrente, isto é, adquiriram as altas notas de entrada por essa via. 
9. A matéria sobre a qual incide o exame de cada disciplina tem de abranger tudo quanto foi ensinado naquela área. Por exemplo, não faz sentido que o exame do $12{ }^{\circ}$ ano de "Química" não possa ter questões com matéria do 8. $, 9 .^{\circ}, 10 .^{\circ}$ e $11 .^{\circ}$ anos. É que as bases destes $8 .^{\circ} \mathrm{e}$ 9. ${ }^{\circ}$ anos são precisamente o que é mais importante ter bem sabido. Similarmente, não faria sentido averiguar os conhecimentos de "Inglês" do $12 .^{\circ}$ ano "dispensando" os dos $7 .^{\circ}, 8 .^{\circ}$ e $9 .^{\circ}$ anos, ou os de Português do $12 .^{\circ}$ ano "dispensando" saber ler e escrever.

Isto deve ficar bem claro sob o ponto de vista legal, pois tem havido graves problemas envolvendo recursos legais. Um desses, por exemplo, envolveu uma questão de "Matemática" do $12 .^{\circ}$ ano onde aparecia o conceito de proporcionalidade. Houve um protesto legal com o ridículo argumento de tal assunto (proporcionalidade) ser de anos anteriores, mas não do $12 .{ }^{\circ}$ ano! E se o examinando se negasse a ler o texto do exame com 0 argumento de que tal era da $1 .{ }^{a}$ classe $\left(1 .^{\circ}\right.$ ano)?

10. Salvo em condições muito excepcionais, as provas de exame devem ser realizadas só em edifícios do Estado e organizadas logisticamente só por personalidades independentes da instituição onde haja alunos candidatos aos exames no espaço físico onde estão a ser realizados. Os organizadores e/ou vigilantes não podem dar qualquer esclarecimento sobre a interpretação do enunciado dos exames. Esta é da exclusiva responsabilidade do examinando. Se este achar que há erros no enunciado, pode declarar isso mesmo na prova, e tal poderá ser tido em consideração, mas não pode esperar nenhuma informação durante os 120 minutos da prova. Parece que no passado tem havido casos em que "vigilantes" dão informações sobre o que é perguntado, colocando assim os alunos em vantagem sobre quem não teve tal informação. Tal é profundamente injusto. Parece mesmo que tem havido casos em que alguém escreve no quadro, ou dita, as respostas pressupostamente correctas às perguntas feitas. Parece até que num protesto de um examinando sobre não Ihe ter sido cotada uma dada resposta, foi alegado ter o examinando escrito escrupulosamente o que Ihe foi indicado durante a realização da prova!

11. Progressivamente devem ser implementados exames nacionais no 9.', 6. ${ }^{\circ}$ e $4 .^{\circ}$ anos do Ensino Básico, em moldes similares aos acima descritos, embora com adaptações óbvias. As alterações que para isso se deveriam introduzir no Ensino Básico estão descritas no ponto 14 , nomeadamente um sistema de escolha livre de disciplinas no $7 .^{\circ}, 8 .^{\circ}$ e $9 .^{\circ}$

[No] Livro Branco de Física e Química mostrase que a maioria dos professores de Física e Química concorda com exames nacionais, e.g. $77 \%$ concordaria com exames no 9. ${ }^{\circ}$ ano.

anos, de forma a que os alunos pudessem inclinar-se mais para as disciplinas de cariz vocacional (e.g. carpintaria) ou académico (e.g. francês) consoante os seus desejos e apetências.

12. Note-se que a existência de exames no ensino básico e secundário terá muitas vantagens para os respectivos docentes.

a) Dá-Ihes muito mais prestígio. O facto de fazerem parte de júris nacionais que decidem, pela via da seriedade, a obtenção de desejados diplomas, confere-Ihes o poder que outrora tinham e faziam com que o prestígio dos professores do Liceu fosse superior ao dos licenciados em direito, medicina ou engenharia. b) Os exames fariam com que o aluno considerasse o professor como um amigo, mas de muito respeito, que o ajuda a passar no tal exame. Como as coisas estão, o aluno considera o professor como um adversário com quem é preciso discutir até que, no caso dos $10 .^{\circ}, 11 .^{\circ}$ e $12 .^{\circ}$ anos, o professor Ihe dê 20 valores, para melhor entrar no curso $X$ ou $Y$. E todos conhecemos casos em que os alunos ou seus pais ameaçaram seriamente os professores dizendo algo como, se em vez de 17 ele desse 18 já o aluno poderia entrar no curso $X$, ou culpando-o de tal pretensão não ter sido atingida. Pior que isso, há casos em que é o próprio Conselho Directivo a pressionar indevidamente o professor.

Também até ao $9 .^{\circ}$ ano o professor estaria numa posição muito melhor na sala de aula se aqueles alunos tivessem depois de se submeter a um exame: ter-Ihe-iam certamente muito mais respeito, mais disciplina e mais amizade, se soubessem que o professor só os admitia a exame se os conhecimentos fossem o suficiente para depois serem aprovados, pois de contrário o professor não correria indevidos riscos.

c) Nas páginas 89 e 90 do Livro Branco de Física e Química mostra-se que a maioria dos professores de Física e Química concorda com exames nacionais, e.g. 77\% concordaria com exames no $9 .^{\circ}$ ano.

13. Tal como as coisas estão, o ensino superior não pode ser eficiente, pois cerca de $80 \%$ dos alunos que entram não têm conhecimentos basilares para poderem entender o que lá se deveria ensinar. E não há outro remédio senão baixar o nível para que o número de reprovações não seja elevado, donde resultam licenciados muito mal preparados, que futuramente serão preteridos em emprego pelos colegas vindos dos países de Leste, ou do resto da U.E. Exames no Básico e Secundário obrigariam os alunos a estudarem mais e consequentemente a entrarem para o Superior mais bem preparados. Dariam também aos pro- 
fessores o prazer de ensinar para quem quer aprender, e não para quem vai às aulas só para passar o tempo, pois sabe que lá passa de ano saiba o que souber. Daria assim muito mais personalidade e gratificação aos professores.

É um enorme desperdício de dinheiro ter alunos no ensino superior a aprender coisas que deveriam ter aprendido antes e, pior ainda, se nunca aprenderem.

14.1 Livre escolha de disciplinas do $7 .^{\circ}$ ao $9 .^{\circ}$ anos de escolaridade. A par das disciplinas "académicas" haveria disciplinas "profissionais" (se preferirem, usem outros vocábulos, e.g. "abstractas" e "vocacionais", etc.) num regime semestral. Assim, ao lado de disciplinas onde se estuda química ou francês, haveria disciplinas onde se estudasse mecânica ou fotografia. Os alunos escolheriam livremente (com ajuda de tutores ou dos pais) as disciplinas dos $3 \times 2=6$ semestres.

14.2 Os anos $10 .^{\circ}, 11 .^{\circ}$ e $12 .^{\circ}$ teriam duas grandes áreas:

a) "Académica", com as seguintes vias:

i) Letras. Daria entrada para todos os cursos das faculdades de letras, direito e similares.

ii) Ciências. Daria entrada para todos os cursos das faculdades de ciências, engenharias, medicinas, agronomias, e similares.

iii) Economias. Daria entrada para todos os cursos das faculdades de economias, gestão de empresas, e similares.

iv) Artes. Similarmente.

b) "Profissional" com os cursos que agora constam dos curricula das escolas profissionais e outros.

14.3 Os alunos teriam o diploma do 9. ano somente por aprovação em 6 semestres, fossem quais fossem. Contudo, a matrícula no $10 .^{\circ}$ ano exigiria um exame de admissão propício à área em que pretendessem matricular-se. Para as áreas "profissionais" a admissão ao $10 .^{\circ}$ ano seria com base numa prova específica da área desejada. Para a área "académica" (qualquer das vias) só seriam admitidos os alunos que fossem aprovados num exame a português, francês, inglês, história e geografia, matemática e ciências (física, química e ciências naturais). Este exame teria duas provas, espaçadas de 3 semanas, das quais seria ecolhida sempre a melhor.

14.4 Os $10 .^{\circ}, 11 .^{\circ}$ e $12 .^{\circ}$ anos das áreas "profissionais" teriam fundamentalmente disciplinas práticas para a área em causa. Alguns assuntos da área académica que fosse preciso dar (e.g. matemática, inglês), sê-lo-iam em moldes e com programa muito diferentes dos da área académica. A presente situação de se pretender dar, nas actuais escolas profissionais, matemática, física, química, etc., com os mesmos programas e escolaridade que na chamada "via ensino" (área académica), é totalmente inaceitável.

A aprovação nas disciplinas da área "profissional" seria adaptada à natureza específica da disciplina. Poderia ser baseada no trabalho ao longo dos 3 anos (e.g. em carpintaria), numa prova prática (e.g. desmontar e montar a embraiagem de um automóvel), numa prova de campo (e.g. levantamento topográfico), ou num exame clássico (e.g. história ou inglês para guias turísticos).

A aprovação no número estipulado de disciplinas daria um diploma profissional.

Os diplomados por esta via profissional poderiam ter acesso ao ensino politécnico mediante exame de entrada específico.

14.5 A partir do final do 9. ano, os alunos teriam de passar parte do tempo em contacto com o mundo do trabalho. Sob a supervisão de professores para tal nomeados, os alunos teriam "estágios" em empresas, hospitais, tribunais, museus, ou quaisquer outros locais de trabalho, onde executariam uma tarefa similar à de qualquer outro trabalhador, integrados na normal hierarquia da instituição em causa. No final teriam um certificado indicando o tipo de trabaIho efectuado, assinado pelo director da instituição e pelo professor supervisor. A admissão a um dado curso superior poderia exigir certos créditos desses certificados. Por exemplo, um candidato a medicina teria de ter $x$ semanas de trabalho num hospital, um a engenharia civil y semanas de activo trabalho na construção civil, etc. Este tipo de contacto com o mundo do trabalho daria aos alunos, e aos professores seus orientadores, um sentido da vida prática muito importante para o respectivo desempenho nas provas de exames.

\section{Notas}

[1] Victor M.M. Lobo, A nefasta artificialidade das provas de "exames" do 12. ano, Química - Boletim da Sociedade Portuguesa de Química, Vol. 83, Outubro-Dezembro 2001, p. 73-75; Victor M.M. Lobo, $A$ "ideologia ensinista" e os exames do 12. ano, Diário de Coimbra, 2 Junho 1998.

[2] Por exemplo, a generalidade dos que têm disciplinas de Química não sabe escrever as mais elementares fórmulas de química (e.g. de cloreto de cálcio), não sabe sequer visualizar os caminhos para chegar à fórmula molecular, isto é, às fórmulas de estrutura (vide Victor M.M. Lobo, A utilidade dos diagramas de Lewis no ensino da Química, Química - Boletim da Sociedade Portuguesa de Química, Vol. 70, 1998, p. 13-17), e não sabe fazer o mais elementar cálculo estequiométrico. Ora isso é matéria do $8 .^{\circ} \mathrm{e}$ $9 .^{\circ}$ anos, mas é precisamente esta a matéria mais importante, é a base, e a que mais mal sabida está. Num exame de Química Geral (89 alunos) quase só sobre a matéria do $8 .^{\circ}$ e $9 .^{\circ}$ anos, a esmagadora maioria dos alunos teve menos de 2 valores! E aí havia alunos que tinham tirado mais de 17 valores no chamado "exame" do $12 .^{\circ}$ ano de Química!!! Então, para que serve essa prova? Mas esta situação é geral: veja-se, e.g., o teste feito pelo Prof. Jorge Buescu a 1200 alunos do Instituto Superior Técnico, onde muitos nem sequer acertaram a soma de 1/2 +1/2!!!!

[3] Vide, e.g., M. Filomena Mónica, Os filhos de Rousseau, ensaios sobre exames, Relógio D’Água Editores, Lisboa, 1997; Gabriel Mithá 
Ribeiro, A pedagogia da avestruz. Testemunho de um professor, Gradiva, Lisboa, 2003 Há também muitos testes, tais como os feitos pelo Prof. Jorge Buescu, onde se mostram as gravíssimas lacunas dos alunos. Há alunos de engenharia que não sabem se $x+$ $x$ é $x^{2}$ ou se será $2 x$ ! Outros dizem saber bem que a área de um triângulo é $\pi r^{2}$ ! Outros (de Geografia) dizem que a Austrália foi colonizada pelo Império Austro-Hungaro, etc., etc.

[4] Informação justificando e esclarecendo melhor estas propostas pode ser obtida em http://www.ci.uc.pt/pessoal/vlobo, ou em Victor M.M. Lobo (A albanização do ensino em Portugal), Jornal Público, 97.07.19; Victor M.M. Lobo (Algumas ineficiências do ensino em Portugal), Jornal Público, 97.08.28;
Victor M.M. Lobo (Escolas profissionais), Jornal Público, 97.12.09; Victor M.M. Lobo (A "ideologia ensinista" e os exames do $12 .{ }^{\circ}$ ano), Diário de Coimbra, 98.06.02; Victor M.M. Lobo (A educação está a ser um colossal embuste), Diário de Coimbra, 98.06.16; Victor M.M. Lobo (Algumas considerações sobre a carreira docente do ensino secundário), Diário de Coimbra, 98.09.15; Victor M.M. Lobo (O ensino secundário e os regimes políticos), Diário de Coimbra, 98.07.29; Victor M.M. Lobo (Nível de conhecimentos para entrar na Universidade), Diário de Coimbra, 98.06.24; Victor M.M. Lobo (Gestão das Universidades), Diário de Coimbra, 98.07.15; Victor M.M. Lobo (A utilidade dos diagramas de Lewis no ensino da química),
Bol. Soc. Port. Quim. 70, 13 (1998); Victor M.M. Lobo (A degradação no ensino), Diário de Coimbra, 98.12.21; Victor M.M. Lobo (Professores e examinadores), Diário de Coimbra, 99.01.07; Victor M.M. Lobo (O ensino e a livre escolha de disciplinas), Diário de Coimbra, 99.01.25; Victor M.M. Lobo (Propostas de alteração no sistema de ensino), Diário da República, II Série, n. ${ }^{\circ} 17$ de 99.01.21, página 829; Victor M.M. Lobo (Os "Exames" do $12^{\circ}$ Ano), Diário de Coimbra, 01.10.12; Victor M.M. Lobo (A falta de conhecimentos básicos dos alunos do $12^{\circ}$ ano), Diário de Coimbra 01.12.10; Victor M.M. Lobo (A nefasta artificialidade das provas de "exame" do $12^{\circ}$ ano) Química (Bol. SPQ) Vol. 83, Out-Dez 2001, p. 73-75.
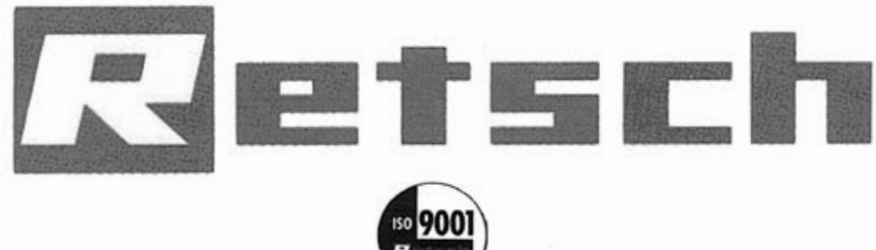

Moinhos
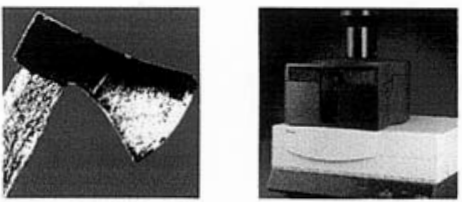

Agitadores de peneiros/peneiros
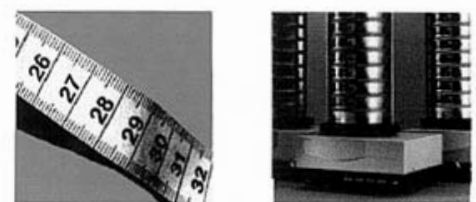

\section{Divisores de amostras}
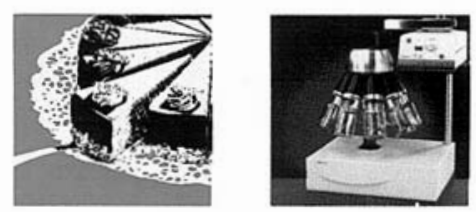

\section{Análise granulométrica automática CAMSIZER / CRYSTALSIZER}

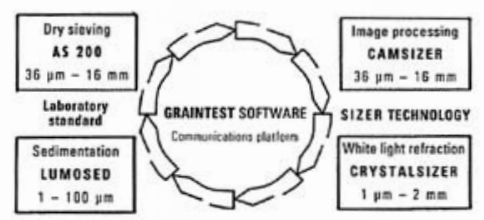

Peça-nos o contacto do agente mais próximo, através dos telefones:

21-352 7293

LSBOA

Campo Mártires da Pátria, 109 Rua do Vilarinho, $1235 \cdot 4100-517$, Port
22-618 4232

07 mportadar Exclusiva 


\title{
- limpíadas \\ 8o e 9o anos de escolaridade
}

\section{Este ano, a nível nacional !!}

\author{
9 de Abril de 2005
}

\section{Informações e inscrições até 15 de Fevereiro de 2005:}

\author{
Aveiro \\ DQ - UA \\ Paulo Ribeiro Claro \\ olimpiadas@dq.ua.pt \\ Tel: 234401538 \\ Fax: 234370084
}

\author{
Braga \\ DQ - UM \\ Teresa Ramalho \\ tramalho@quimica.uminho.pt \\ Tel: 253604373 \\ Fax: 253678983
}

Coimbra

DQ - UC

Sérgio Seixas Melo sseixas@ci.uc.pt Tel: $239852080 / 854463$

Fax: 239827703

\section{Covilhã}

DQ - UBI

Helena Bandeira

bandeira@ciunix2.ubi.pt

Tel: 275319730

Fax: 275319730

Évora
DQ - UEvora
António Manuel Neto Vaz
nvaz@uevora.pt
Tel: 266745311
FAX: 266745394

Évora

Faro

DQ - UAlg

Ana Rosa Garcia argarcia@ualg.pt Tel: 289800905 Fax: 289819403
Lisboa

IST, ITQB, DQ-UL, DQB-UNL

(Sede da SPQ)

geral@spq.pt

Tel: 217934637

FAX: 217952349
Porto

DQ - UP

Maria das Dores Ribeiro da Silva mdsilva@fc.up.pt

Tel: 226082794

Fax:226082959
Funchal DQ - UMadeira Helena Figueira da Silva quimica@uma.pt Tel: 291705100 Fax: 291705149
Vila Real

DQ - UTAD

Lucinda Reis quimica@utad.pt Tel: 259350273 Fax: 259350480 